\title{
Las minorias religiosas en el siglo XIX: La Unión Cristiana de Jóvenes de San Fernando (Cádiz)
}

\author{
PEDRO CAVADA MARTINEZ \\ ESTHER VIDAL ROSELLO
}

\section{INTRODUCCION}

Si partimos de la afirmación que la animación ha existido siempre como una educación difusa, intentando potenciar la colaboración y las relaciones de grupo, no sólo en lo que hace referencia al tiempo de trabajo, sino también al tiempo libre y la cultura. Si la animación se caracteriza por su dimensión asociativa basada en el voluntarismo y la gratuidad, es bueno recordar la definición de la UNESCO (1) a la hora de estudiar los antecedentes históricos de lo que hoy se entiende como "animación sociocultural".

La animación dentro de la iniciativa privada, laica o religiosa, se ha dado sobre todo de cara a la enseñanza no convencional, para suplir las deficiencias estructurales del momento. Así, aparecen los Ateneos populares, sostenidos por las cotizaciones de sus socios, con la difusión de la cultura como principal objetivo (2); otras asociacio-

(1) PEREZ SERRANO, Gloria y MARTIN GONZALEZ, María Teresa: "La animación socio-cultural". Madrid: UNED, Programa de Enseñanza Abierta a Distancia, [c.a. 1987], tomo I, p. 100. "En un sentido amplio la UNESCO ha definido la animación sociocultural como un conjunto de prácticas sociales que tienen como finalidad estimular la iniciativa y la participación de las comunidades en el proceso de su propio desarrollo y en la dinámica global de la vida sociopolítica en que están integradas..."

(2) Ibídem, p. 336. 
nes, dentro de unos marcos ideológicos y políticos concretos, con actuación en un determinado ámbito de la población, como las mujeres (3), y el movimiento asociativo de carácter religioso y juvenil, como veremos en las líneas siguientes.

\section{LAS UNIONES CRISTIANAS DE JOVENES}

Tal vez las siglas Y.M.C.A. (4), su versión femenina Y.W.C.A. (5) o su equivalente francés U.C.J.G. (6) no sean familiares para el lector español. Mas si recuerda novelas del campo anglosajón las verá convertidas en lugares comunes, sobre todo si en ellas se relata o refleja la dinámica social de fines del siglo pasado o inicios del presente (7).

Este movimiento asociativo lo ve Léonard como producto del "Reveil", "despertar" religioso, hijo de la Restauración política surgida del Congreso de Viena de los años 1814 y 1815 (8). Antes de que su fundador oficial, George Williams, inaugurara su "Unión" en Londres, en 1844, ya existen precedentes de este movimiento un siglo antes. Podemos señalar una "Unión" de jóvenes en Glasgow, en 1725, o en Basilea, en 1768 (9). A efectos de fijación cronológica, la "puesta de largo". de este movimiento fue en París, donde tuvo lugar la primera Conferencia universal el 23 de agosto de 1855 (10). Siendo la pretensión ecuménica de esta federación, en palabras de su fundador, como se cita:

"La Unión es un terreno neutral sobre el que pueden encontrarse, en la mayor fraternidad, los miembros de toda congregación y de toda confesión; cada uno de sus afiliados debe estar atento a la importancia vital de pertenecer a una Iglesia cristiana de su elección" (11).

(3) Por ejemplo, "Sociedad Republicana Federal Mariana de Píneda", de 1870. Archivo Municipal de Cádiz (en adelante AMC), caja n 493, "Asociaciones y Sociedades".

(4) MARTINEZ DE SOUSA, José: "Diccionario internacional de siglas y acrónimos”. Madrid: Pirámide, 1984, p. 548 “...World Alliance of Young Men's Christian Associations (Alianza Mundial de Asociaciones Cristianas de Jóvenes)..."

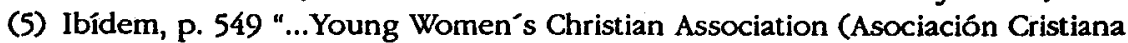
Femenina Mundial) ...Antes, Asociación Cristiana de Mujeres Jóvenes..."

$(6)$ Ibidem, p. 505 "...Unions chrétiennes de jeunes gens (Uniones Cristianas de Jóvenes), Francia..."

(7) Podemos citar sólo a título de ejemplo "El paralelo 42", de John Dos Passos, - "Cárceles de mujeres", de Sinclair Lewis.

(8) LEONARD, Emile G.: "Historia general del protestantismo". Barcelona: Ediciones 62, 1967 (Colecciones Península), tomo III, p. 145.

(9) Ibídem, p. 401.

(10) Ibídem, p. 403.

(11) Ibidem. 
A este movimiento pertenecieron figuras célebres como Henrỳ Dunant, miembro fundador de la "Unión de París", en 1852, y fundador de la Cruz Roja (12), o el general Robert Stephenson Smyth Baden-Powell, fundador del escultismo en 1908, que enriquecería en sus métodos de educación la obra de las Uniones Cristianas de Jóvenes (13). Este movimiento asociativo juvenil, no sólo apareció en el contexto anglosajón y protestante; para el mundo católico, Sáez Marín data a mediados del XIX la fundación de Don Bosco de su obra del "Oratorio Festivo" en las ciudades industriales de Italia (14), afirmando además que cronológicamente las asociaciones y organizaciones cristianas de jóvenes son anteriores a todas las demás.

En España, las Uniones Cristianas de Jóvenes penetran paralelamente a lo que la historiografía protestante denomina "Segunda Reforma" (15), que a efectos de periodización parte de la proclamación de la Constitución en 1869 , que contenía por vez primera un artículo -el 21- por el cual se legislaba la implantación de un sistema de tolerancia religiosa en España (10). La acogida tuvo que ser buena en los lugares donde el protestantismo arraigó, ya que en algunas Uniones de Jóvenes españolas era mayor el elemento católico que el protestante, a pesar de vivir estos organismos en pleno contacto con las Iglesias Reformadas y sus pastores (17). Llegan a perdurar hasta mediados de este siglo; Gutiérrez-Marín señala en su libro, publicado en 1942, que las "Uniones" se hallan establecidas en las grandes capitales como Madrid, Barcelona, Sevilla y Valencia (18). Tenemos constancia que en épocas anteriores, en el último tercio del XIX, la expansión fue algo mayor (19).

(12) Ibídem, p. 401.

(13) Ibídem, pp. 404-405.

(14) SAEZ MARIN, Juan, "Asociacionismo juvenil en Europa hasta 1940 (Noths para su Estudio, 1$)^{n}$ en De Juventud: revista de estudios e investigaciones. Madrid: Ministerio de Cultura, Dirección General de Juventud y Promoción Sociocultural, $n^{2} 5$, enero-marzo, 1982, pp. 38-39.

(15) GUTIERREZ-MARIN, Claudio: "Historia de la Reforma en España". México, D.F.: Casa Unida de Publicaciones, 1942, p. 5.

(16) SALADRIGAS, Robert: "Las confesiones no católicas de España". Bárcelona: Península, 1971 (Ediciones de bolsillo), p. 29.

(17) GUTIERREZ-MARTIN, op. cit..p. 422.

(18) Ibidem, p. 423.

(19) En el archivo de la Iglesia Evangélica de "El Buen Pastor" (en adelante AIEEEBP), de San Fernando, caja $n^{\mathbf{2}} 15$, se conservan ejemplares de "A las Uniones Cristianas de España", circular manuscrita y litografiada publicada intermitentemente por Francisco Albricias entre 1879 y 1890, que informaba de las "Uniones" en España y el extranjero. Para España da noticias de "Uniones" en Zaragoza, Jerez de la Frontera, Valladolid, Oviedo, Cádiz, Huelva, etc. 
Siguiendo a Menéndez Pelayo (20), ya en 1873 las autoridades municipales hicieron cerrar la capilla de la Iglesia del Buen Pastor. El 15 de febrero de 1875 se nombró una nueva Junta Evangélica para regir su reorganización (21). La "Unión" se funda el 27 de septiembre del mismo año, en los locales de la Iglesia, en la calle de San Bernardo $n^{\circ} 55$ (22). Para fijar los límites cronológicos de esta asociación tenemos que ceñirnos a las actas que se conservan (23) sin tener la seguridad de que sean todas.

La composición organizativa de esta entidad era similar a la que pudiera darse en cualquier otra asociación, es decir, formada por una junta general de socios y otra directiva, elegida en el seno de la primera. En el momento de su constitución se nombró interinamente un Presidente y un Secretario. En febrero de 1878 la composición de la junta directiva ya está delimitada, y queda comprendida por los siguientes cargos: Presidente, Secretario, Tesorero, Bibliotecario, sub-Bibliotecario y dos Vocales.

Como en otras organizaciones, los candidatos tenían que ser presentados por dos socios activos y pasar un período de prueba hasta su admisión en firme en acto público, donde firmaba un extracto de los estatutos y recibía su correspondiente "Carta-miembro", entrando así como miembro de pleno derecho. La edad reglamentaria de los asociados era de 15 a 30 años. Y para los que excedían esa edad fueron creándose las categorías de "miembro honorario" y "miembro suscriptor". La composición numérica de esta "Unión" era pequeña, según las relaciones de asistentes en las actas, nunca pasaron de 30 sus miembros activos.

Lamentablemente, no se conserva ningún ejemplar de los reglamentos que sucesivamente rigieron esta "Unión". Sí consta que los reglamentos eran discutidos en las reuniones para su redacción y aprobación, ocupando buena parte del orden del día, y se reformaron a menudo. Así, el reglamento que se elaboró entre los meses de sep-

(20) MENENDEZ PELAYO, Marcelino: "Historia de los heterodoxos expañoles". Madrid: Editorial Católica, 1956 (Biblioteca de Autores Cristianos), tomo II, p. 1146.

(21) AIEEEBP, libro $n^{\circ} 11$.

(22) Ibídem, libro $n^{2} 20$.

(23) Ibídem, libro $n^{\circ} 20$ (1875-1882), libro $n^{\circ} 21$ (1882-1898) y libro $n^{2} 22$ (1898-1906). 
tiembre y octubre de 1875 se empezó a reformar en noviembre de 1879 , culminándose las reformas en enero del año siguiente, para ser reformado nuevamente en los años 1882, 1899 y 1901.

Figura en el acta una adición que se la hizo el art. $1^{2}$ (Cap. I), el 7 de octubre de 1875: "... independiente de toda institución eclesiástica". Suponemos que este artículo se referiría a la personalidad y fines de la institución. Pero quizá podemos hacernos una idea con el extracto de los reglamentos de la "Unión" de Huelva, publicado en "A las Uniones Cristianas de España" ( $n^{\circ} 15$ - mayo, 1881): (24)

"Cada miembro activo paga para los gastos de la Sociedad una peseta de entrada y otra por cuota mensual (cap. II, art. 8).

El objeto principal de esta "Unión" es la mutua instrucción de sus miembros en las doctrinas y espíritu del Evangelio, y en todos aquellos conocimientos que puedan ser útiles al hombre; su mutuo aliento en el camino de la verdad, en la caridad fraternal y en las obras propias de todo cristiano... etc. (cap. I, art. 2).

La Unión celebrará una reunión semanal, para clase bíblica, polémica sobre diversos puntos de doctrina: una conferencia científica todos los quince días (cap. IV, 17 y 18).

La Unión tiene clase de noche tres días a la semana para sus miembros..."

La situación financiera de esta "Unión" fue siempre uno de sus puntos álgidos, dado el poco número de sus miembros y que se sufragaba sólo con las cuotas de sus socios. La única ayuda documentada que recibió fue gracias a la solidaridad de la "Unión" de Edimburgo, en 1876. No obstante, con tan exiguos recursos, la "Unión". se relacionaba con todas sus homólogas en España y mantenía correspondencia regular con el Comité Central Internacional de la Y.M.C.A. Tenemos datos de la aportación para los gastos del delegado español, Francisco Albricias, en su asistencia al $9^{\circ}$ Congreso Unionista, celebrado en Londres en agosto de 1881 , siendo el importe de "cinco duros" o, rayando en la anécdota, el costo de una carta enviada a la "Unión" de Valladolid en 1878: 1/4 de real de vellón. Asimismo, en un ámbito más local, este grupo colaboró en la organización de dos Congresos provinciales de las "Uniones", celebrados en El Puerto de Santa María en los años 1881 y 1883.

(24) Ibídem, caja n 15 . 
Retomando el tema de las finanzas, los ingresos se producían fundamentalmente por dos vías: las cuotas de los socios, que nutrian diversos fondos administrados por distintas personas, y las cuotas de los alumnos no socios de la "Escuela nocturna", que eran recaudadas por el bibliotecario para engrosar el fondo específico de la biblioteca.

Los fondos constituidos eran los siguientes:

19) Fondo de biblioteca, administrado por el bibliotecario, destinado a adquisiciones bibliográficas.

$2^{2}$ ) Fondo general, administrado por el tesorero, con el que se satisfacía el importe de los gastos generales (alumbrado, mantenimiento de locales, material de escritorio, etc.).

$3^{\circ}$ ) Fondo para la publicación del periódico, destinado a la fundación de un órgano de expresión común a todas las "Uniones" de España. Este proyecto se cristalizó, pensamos, con "El Atalaya", de aparición irregular, fundado por Francisco Albricias, y que dejó de publicarse en Alicante en 1919 (25).

$\left.4^{\circ}\right)$ Fondo para las escuelas, constituido por el $5 \%$ de la recaudación trimestral, con el objeto de fundar una escuela. No nos consta que se llevara a cabo.

$\left.5^{\circ}\right)$ Fondo de caridad, administrado por el presidente, con las bases siguientes:

"12) La colecta de caridad se recogerá en todas las sesiones y servirá para socorrer a los jóvenes transeúntes cristianos.

$\left.2^{2}\right)$ También servirá para socorrer a los miembros de esta Unión que estando enfermos tuvieren necesidad de ayuda.

3) Habiendo más de 20 r. se podrá socorrer a un joven transeúnte aunque no sea cristiano."

$\left.6^{\circ}\right)$ Fondo de evangelización, administrado por un vocal, cuyos ingresos provenían del producto de rifas benéficas entre los miembros de la congregación. Su finalidad era "reunir para la obra de la Unión y ayudar a las demás de España".

$7^{\circ}$ ) Fondo para la casa, proyecto frustrado de adquirir un local propio de la Unión.

De todas maneras, conviene no perder de vista lo modesto de las cantidades; en la sesión del 9 de julio de 1882, por ejemplo, el estado de cuentas final, el líquido, es el que a continuación reproducimos:

(25) GUTIERREZ-MARIN, op. cit., p. 412. 
"Fondo General en proporciones:

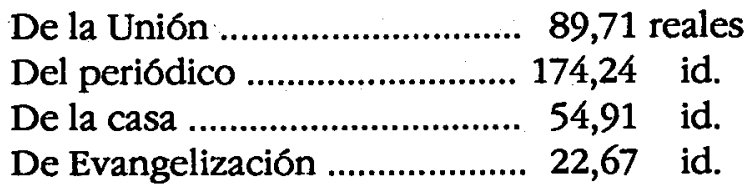

Suma r.v. $341,53^{n}$

A partir de estas líneas vamos a centrarnos en una enumeración suscinta de las actividades que llevaba a cabo este grupo. Pero tal vez sea conveniente indicar algo del marco sociológico y cultural de la época. La sociedad española de la segunda mitad del siglo XIX era una sociedad primordialmente rural, con un incipiente flujo de población hacia las áreas en vías de industrialización; una sociedad mayoritariamente analfabeta, de lo cual era sensible la sociedad misma y su clase dirigente. Los tímidos intentos de fomentar la enseñanza primaria por parte de los poderes públicos en las primeras décadas del siglo no dieron al parecer el fruto adecuado. En 1857, la Ley Moyano indica en su artículo 106 que "el gobierno fomentará el establecimiento de lecciones de noche y de domingo para los adultos cuya instrucción haya sido descuidada o quieran adelantar en sus estudios". El censo de 20 años más tarde informa que un $72 \%$ de la población española era analfabeta, concretándose las cifras de analfabetismo en un $62 \%$ para varones y un $81 \%$ para mujeres. Diez años después estas cifras sólo varían en décimas más o menos (26). Vemos, pues, que el acceso a la educación era un bien escaso, y para subsanar esta realidad se crearon organizaciones de todo tipo con el objetivo de la instrucción como denominador común; de esto damos una pequeña muestra en el Apéndice del presente trabajo.

La "Unión" empezó de una forma modesta en este campo de actuación: el día de su fundación acordó dedicar parte de las sesiones a la enseñanza literaria, fijándose para ésta los jueves. Pasado un mes se amplían las clases de instrucción a lunes, jueves y viernes, con hora y media de duración al día, encargándosele al pastor de la Congregación la formación de un plan de estudios. El acceso a estas clases era

(26) Citado en "Historia de España" / dirigida por Manuel Tuñón de Lara. Barcelona: Labor, 1987, tomo VIII, p. 324. 
en principio restringido a los miembros de la Sociedad, aunque pòdían beneficiarse personas ajenas a ésta con el acuerdo de los socios. el 21 de febrero de 1876 se aprobó por unanimidad una proposición que decía así:

"'13) Los jóvenes menores de 15 años que desean participar de la instrucción que la Unión Evangélica tiene establecida solo pueden ser admitidos mediante una garantía de dos o mas de los miembros activos.

$2^{2}$ ) Deberán satisfacer medio real [de vellón] mensual para los gastos de las escuelas, dejando de asistir a ellas si por su voluntad faltase en pagar esta cuota dos meses seguidos."

Pero meses más tarde del mismo año "...el Presidente propuso como necesario para el desarrollo de la Unión, que la misma se prestase a enseñar a leer y a escribir a cuantos lo solicitasen, sin más formalidad que escribir sus nombres en el Registro de la Secretaría", siendo también aprobado por unanimidad.

La "Unión" asumía con cargo al Fondo General los gastos de esta "Escuela de adultos nocturna", dándose cuenta en las actas de gastos efectuados en cabos y cajas de plumas, cuadernos de papel de diversas clases, etc... Paralelamente, los socios dedicaban parte de sus sesiones a la instrucción, comenzando por clases de Ortografía y ampliándose en marzo de 1880 a la enseñanza de Gramática Castellana, Aritmética y Geografía. El profesorado de estas disciplinas era reclutado entre los mismos socios "que se consideren competentes y con los conocimientos necesarios para enseñar", contando para las clases de Geometría con un prohombre del protestantismo español, Juan Labrador Sánchez, en aquel entonces Condestable-alumno de la Academia de Artillería de la Armada, y que llegaría a alcanzar el grado de General de este Cuerpo (27). También se contaba con el profesorado de las "Escuelas Cristianas", escuela de enseñanza primaria que la Iglesia sostenía en sus mismos locales. Este fenómeno de escuelas protestantes era ya que, en palabras de Fernández Campos, la instalación de una escuela, en muchos casos, solía ser el primer acto de presencia evangélica en una ciudad durante el siglo pasado (28). Esta

(27) FERNANDEZ CAMPOS, Gabino: "Reforma y Contrarreforma en Andalucia: historia". Sevilla: Editoriales Andaluzas Unidas, 1986 (Biblioteca de la Cultura Andaluza), p. 231-236.

(28) Ibídem, p. 180. 
"Escuela de adultos nocturna" siguió su guadiana a tenor de las circunstancias, subsistiendo en la documentación de que disponemos hasta 1904. Parece ser que, a pesar de todo la labor de la "Escuela" se amplió a todos los días de la semana, con la excepción de los domingos; al menos así lo refleja el acta del 13 de junio de 1901, donde se establece un cuadro de profesores hasta las vacaciones.

Menéndez Pelayo se queja en su obra del "frenético espíritu irreligioso" de los años 1868 a 1882 (29). Sin embargo, en este contexto de secularización política es donde el protestantismo penetra en España y se arraiga en numerosas ciudades, con unas actitudes propias hacia el hecho religioso y hacia la convivencia dentro de su confesión. En el aspecto religioso y convivencial esta "Unión" exigía a sus miembros activos un compromiso firme, siendo causa de separación de la Sociedad la maledicencia y las faltas de asistencia injustificadas, previo dictamen de la Comisión de Justicia y Caridad (o Beneficencia), constituida en la sesión del 19 de marzo de 1901.

Los métodos de cohesión grupal eran varios: se empezó estableciéndose la visita dominical a la casa de algún miembro; sirviendo más tarde estas casas de local para culto de oración y estudios bíblicos. Estas reuniones en casas particulares se extendieron al parecer a hogares de personas que no eran miembros activos, pues a principios de 1905 se tuvo que establecer la diferencia "...que en las casas de los socios serán Reuniones, hablarán todos, haciendo el Presidente al final un Resumen. En las casas de no socios serán Conferencias y dirigirá la palabra el Sr. Presidente y hablará el que quiera: un estudio será en casa de un socio otro en casa de un no socio y así sucesivamente." En esta misma sesión, de 3 de enero de 1905, se consignan hasta seis casas ofrecidas a la "Unión". Otro método era el establecimiento de días y horas señaladas para paseos y excursiones conjuntas, buscando una imagen atractiva a fin de atraer jóvenes a la Sociedad. Otra actividad de cara al fomento y crecimiento de la "Unión" fue la venta de refrescos en sus locales, iniciada en junio de 1901 y abandonada dos meses más tarde. Para la actividad de los domingos se acordó en marzo de 1902 lo siguiente:

"1\% Domingo.

Estudio Bíblico o Conferencia.

$2^{\circ}$ Domingo.

Paseo. No es obligatorio. Los que buenamente quieran.

(29) MENENDEZ PELAYO, op. cit., Pp. 1.120-1.141. 


\section{$3^{\circ}$ Domingo.}

Estudio Biblico o Conferencia. Esto si el primer Domingo ninguno lo ha dado; - solo puede darse una al mes: —bien sea el $1^{\circ} \hat{u}$ el $3^{\circ}$ domingo. $4^{\mathbf{2}}$ Domingo.

Culto familiar en la Casería."

De inspiración y contexto protestante, la "Unión" intentó realizar una labor de evangelización dentro del sector de la población que más demandaba sus servicios educativos, es decir, la población más humilde de San Fernando. Pretendió hacerlo mediante los clásicos tratados, pero sin medios económicos para adquirirlos en cantidad suficiente. Los barrios elegidos por la "Unión" para su evangelización fueron las "Callejuelas" y la Casería de Ossio, que eran barrios de pescadores, mariscadores y salineros, que en aquella época y en la actualidad conforman las zonas deprimidas y marginales de la ciudad.

Aunque este grupo tuvo que recurrir más de una vez al pastor en tiempos de crisis - y de hecho el pastor era miembro nato fácilmente- y buena parte de sus miembros pasaron a engrosar el número de los profesos de la Iglesia, institucionalmente la Unión Cristiana de Jóvenes de San Fernando mantenía relaciones de independencia con la Iglesia que facilitaba sus locales; a una proposición hecha en 1899 "que porqué no se hacía un esfuerzo para que cantase, orase y hablara en la capilla los domingos cada uno de los que formaban la Sociedad díjose que tal proposición tenía un carácter demasiado oficial". Sí eran más regulares como corporación las relaciones con las "Escuelas Evangélicas". (también se denominaban asî), de donde salía parte del profesorado de la enseñanza nocturna de la "Unión" y con las que se colaboraba todas las Navidades en las fiestas que se organizaban para los niños, encargándose el grupo de la organización material de las fiestas y subvencionando con cargo a su Fondo General y mediante suscripciones específicas el costo de las golosinas, refrescos y premios.

Se organizaban también reuniones conjuntas de los socios de la "Unión", los miembros de la Congregación y los niños de las "Escuelas". De cara al exterior, tenemos documentadas la organización de veladas literarias todos los años, de 1902 a 1905 , ocupando los pormenores de la organización buena parte de las sesiones, en las que se nombraban comisiones para los distintos trabajos requeridos con tal finalidad. En esas veladas se ofrecía un refrigerio, se recitaban poemas, se daban conferencias, audiciones musicales e incluso sesiones de "Linterna mágica". Esto último no nos debe sorprender, ya que 
según Rafael Garófano, estudioso del medio cinematográfico en Cádiz, "la utilización en Cádiz [y su entorno] de Linternas Mágicas, como espectáculo de ferias y veladas, hacía ya muchísimos años que se venía haciendo cuando, en 1896, llegó el cinematógrafo. Pero es a partir de esta época, cuando vemos la supervivencia de este original aparato de proyecciones en diversos usos y en variados locales y circunstancias" (30).

Otro elemento de relación externa de la Sociedad fue la organización en 1881 de una "Sala de lectura de novelas contando con varios periódicos religiosos y políticos y los libros de la Biblioteca". Incidiendo en las relaciones externas, para terminar, en 1899 se propuso en sesión "...que se alquilase un local a fin de darles lecciones a los jóvenes que a ella concurriesen, con tal carácter que fuese desapareciendo el miedo y recelo de algunos jóvenes en asistir a nuestras reuniones... se vió con sentimiento que no podía llevarse a cabo tan buena idea por falta de recursos para ello." Mas a pesar de frustrarse este proyecto, la "Unión" contaba con las casas particulares e incluso con un local en las "Callejuelas", alquilado por la Congregación, para sus actividades. Pero nunca llegó a tener un local propio que le permitiera mayor independencia.

\section{APENDICE \\ EXTRACTOS DE ESTATUT'OS Y REGLAMENTOS (31)}

Artículo $1^{\circ}$. Con el nombre de Centro de Amigos de Puerta Tierra, se constituye una Sociedad que tendrá por principal objeto:

19) Establecer, cuando la situación lo permita, cooperativas de consumos y clases para enseñanza, donde podrán recibir educación gratuita los hijos de los asociados.

Artículo $4^{\circ}$. Los socios satisfarán la cuota semanal de dos pesetas excepto los obreros que solo abonarán una peseta a juicio de la Junta Directiva.

Artículo $11^{\circ}$. La Junta Directiva se compondrá de un Presidente: un Vice-presidente; un Secretario; un Vice-secretario; un Contador; un Depositario; un Bibliotecario y seis Vocales.

[Cádiz, 27 de octubre de 1917.= Presentado a los efectos de la Ley de Asociaciones. Cádiz, 29 de octubre de 1917].

(30) GAROFANO SANCHEZ, Rafael: "El cinematógrafo en Cádiz: una sociología de la imagen (1869-1930)". Cádiz: Fundación Municipal de Cultura, Catedra "Adolfo de Castro", 1986, p. 31.

(31) AMC, caja n 493. 


\section{CAPITULO 1은}

Art. 19. Esta Sociedad será Republicana Federal y demócrata titulada de Mariana Pineda.

Art. $2^{\circ}$. La dirección y administración de la Sociedad queda a cargo de una junta compuesta de una Presidenta, Vicepresidenta, 4 Vocales, Tesorera y Secretaria.

Art. $3^{\circ}$. La Sociedad tiene por objeto la instrucción de la mujer y el conocimiento de sus derechos y deberes en toda su latitud y el mejoramiento de su clase a cuyo fin se le instruirá dentro de las doctrinas democráticas federales.

Art. $5^{9}$. Establecerá cátedras de instrucción elemental y superior a medida que lo permitan sus recursos.

\section{CAPITULO 20}

Art. 5\%. La Socia que dejara de satisfacer durante dos meses su cuota será requerida al pago y si no lo hace la junta dispondrá lo más conveniente a la Sociedad.

[Expediente de Alcaldía n 349, diciembre de 1870]. 